\title{
How resource-efficient is the global steel industry?
}

\author{
Ana Gonzalez Hernandez ${ }^{a}$, Leonardo Paoli ${ }^{a}$, Jonathan Cullen ${ }^{a}$ \\ Department of Engineering, University of Cambridge, Cambridge, United Kingdom
}

\section{Introduction: resource efficiency in the steel sector}

The production of steel, a key enabler of modern societal development, is responsible for over a quarter of industry's carbon dioxide $\left(\mathrm{CO}_{2}\right)$ emissions (IEA, 2016). The International Energy Agency's (IEA) $2^{\circ} \mathrm{C}$ scenario for 2050 suggests that more than a third of the emissions reduction in industry (excluding power generation) will come from the steel sector, making steel the single largest contributor to industrial emissions reduction. Energy efficiency (EE) and material efficiency (ME) strategies, the combination of which is defined as resource efficiency (RE) in this article, are expected to deliver significant emissions reductions in the short term, especially while decarbonisation technologies such as smeltreduction and carbon capture and storage are still under development. In fact, in their Material Efficiency Scenario, the (IEA, 2015a) shows "material efficiency could deliver larger energy savings in energy-intensive industries than energy efficiency" especially in the steel industry.

Customarily, to determine the improvement potential available from EE, the scale of the energy flows in a system is traced, and both a current and a target efficiency are defined. Yet performing a similar task for industry, where the main product outputs are materials, cannot be appropriately accomplished by solely evaluating the flows and efficiency of energy. In real industrial processes, including steelmaking, material and energy inputs interact and undergo chemical reactions to produce a range of energy and material products. Neglecting materials when analysing industrial RE only provides a myopic picture. To quantify the potential resource and emissions savings in the steel industry, a holistic understanding of both types of resources and appropriate metrics that capture their interactions is needed.

In this paper, a more complete RE metric is used, based on exergy, to measure the efficiency of energy and material use in the steel industry. By integrating energy and materials into a single measure, it is possible to consolidate a range of efficiency interventions: reducing energy/fuel inputs; reducing raw material inputs by improving material yield (Milford et al., 2011); recovering energy by-products (i.e. waste heat and waste gases); recovering by-product materials, i.e. slag and sludge (Canadian Steel Producers Association, 2007; ESTEP/EUROFER, 2014; European Commission, 2009); shifting production to scrap-based steelmaking (Cullen and Allwood, 2012; Pauliuk et al., 2013). This study sets out to answer three research questions:

- How resource efficient is the steel industry today?

- What is the current heterogeneity of the RE between steel plants and production routes?

- What is required to raise today's average performance to best practice?

\section{Previous work: energy and material efficiency studies}

Most efficiency studies of the steel industry focus on either EE or ME. These studies are reviewed first, before introducing a third type of study that uses exergy to conduct an integrated analysis of energy and materials.

Energy efficiency studies are common in academia, industry and policy-making, and typically employ energy intensity metrics to identify potential energy savings. Worrell et al. (2008) published perhaps the most widely cited study of energy use in the steel industry. The analysis evaluates high performance reference plants, based on data from the International Iron and Steel Institute (IISI, 1998), with energy intensities (GJ/t of physical unit of output) reported at the level of fuels, steam and electricity inputs. A joint study by the European Steel Technology Platform (ESTEP) and European Steel Association (EUROFER) went further to breakdown fuel inputs by type, i.e. natural gas and oil (ESTEP/EUROFER, 2014). Similar energy-intensity studies have also been produced by national bodies, such as the Canadian Steel Producers Association (Canadian Steel Producers Association, 2007).

Phylipsen et al. (1997) proposed a modified energy intensity metric called the Energy Efficiency Index (EEI), which enables the comparison of industrial EE between countries (Phylipsen et al., 1997). The EEI metric accounts for structural effects by measuring the ratio of average and best practice energy intensity for each country. This method has been applied: to benchmark industry sectors in the Netherlands (Phylipsen et al., 2002); in detailed EE studies of steelmaking processes (Arens and Worrell, 2014; Siitonen et al., 2010); and in global benchmarks (Saygin, 2012; UNIDO, 2010). In policy, the (European Commission, 2016) tracks EE improvements using the ODEX index, which 
transforms energy intensity values into rates of energy savings in percentages. These studies all use energy intensity metrics to track and estimate energy-related savings.

Many studies predict the future emissions and energy use of the sector, such as (IEA, 2017a; Kuramochi, 2016; Morfeldt et al., 2015; OECD/IEA, 2007; Saygin, 2012; van Ruijven et al., 2016; Zhang et al., 2018). Within these, Saygin (2012) estimates that $6.1 \pm 19 \%$ EJ/year can be technically avoided, whereas the IEA (2007) predicts between 2.9 and 5 EJ/year. These forecasts, however, disregard the entire gamut of ME strategies showed by (Allwood et al., 2010a) to be indispensable in achieving the agreed emissions reductions.

Material efficiency studies are less common as they require knowledge of larger sections of the supply chain. Allwood and Cullen (2012) outline six key ME strategies for energy-intensive materials such as steel: (1) using less by design; (2) reducing yield losses; (3) diverting manufacturing scrap; (4) re-using components; (5) designing longer life products; and (6) reducing final demand. Recent studies have attempted to assess the potential energy or emissions savings from these strategies. For example, Milford et al. (2011) calculated the savings available from yield improvements across various steel and aluminium supply chains. Whereas, Cooper et al. (2014) explored component-level strategies for extending the lifespans of steel products. Only two studies were found that include ME strategies as part of forecasting exercises: studies performed by (Milford et al., 2013) and (IEA, 2015a). Other studies have examined strategies for recycling and re-use, employing metrics such as recycling rates $(\%)$, recycled content (\%), scrap diversion (\%); re-use rates (\%), material intensities (tonnes per area, volume or service) (Allwood, 2014; Allwood et al., 2010b; Cullen and Allwood, 2012; Densley Tingley et al., 2017; Graedel et al., 2011). Embodied energy (GJ/t) and emissions $\left(\mathrm{tCO}_{2} / \mathrm{t}\right)$ also provide measures of cumulative savings, and are useful for making comparisons between ME options.

EE and ME measures are difficult to combine because they are measured in different units. To resolve this, academics in the later 1980s began using exergy (based on the work by Keenan (1932) and Rant (1956), among others) as a measure of both energy and materials in resource accounting studies. Szargut (1986) defined chemical exergy as the potential of a substance to do work due to its difference in chemical composition with respect to the environment. This development in the calculation of the chemical exergy of materials made it possible to apply exergy in industrial processes, for example: chemical reactors (Brodyansky et al., 1994; Sorin and Paris, 1998; J Szargut et al., 1988) and manufacturing processes (Branham et al., 2008; Gutowski et al., 2009).

Today, exergy analyses have been applied to steel production: at the country level, for the US (Masini and Ayres, 1996), China (Wu et al., 2016), and the UK (Michaelis et al., 1998); for specific technologies (blast furnaces (Petela et al., 2002), electric furnaces or sintering processes (Bisio, 1993), smelting process (Akiyama and Yagi, 1988; Ostrovski and Zhang, 2005)); across individual or a combination of reference plants (Costa et al., 2001; J Szargut et al., 1988) (de Beer et al., 1998). Some of these exergy analyses of steel production only give results as exergy intensities; those that provide efficiency metrics are summarised in Table 1.

Table 1- Exergy efficiency values found in the literature. (CO-coke oven; SI- sinter plant; PE-pellet plant; BF-blast furnace; BOS - basic oxygen steelmaking; EAF - electric arc furnace; DRI - direct iron reduction; HSM - hot strip mill; PP - power plant.

\begin{tabular}{|c|c|c|c|c|c|c|c|c|c|c|c|c|}
\hline Reference & Scope & $\mathrm{CO}$ & SI & PE & $\mathrm{BF}$ & BOS & EAF & DRI & HSM & PP & BF-BOS & DRI-EAF \\
\hline $\begin{array}{l}\text { (Szargut et } \\
\text { al., 1988) }\end{array}$ & $\begin{array}{l}\text { Case } \\
\text { study }\end{array}$ & 78.5 & - & - & $28-59$ & $85-92$ & 52.2 & - & - & - & $29-30$ & 34.0 \\
\hline $\begin{array}{l}\text { (Masini and } \\
\text { Ayres, 1996) }\end{array}$ & USA & $83-90$ & 4.3 & 15.7 & 44.8 & 67.6 & - & - & - & - & 36.1 & - \\
\hline $\begin{array}{l}\text { (de Beer et } \\
\text { al., 1998) }\end{array}$ & $\begin{array}{l}\text { Referen } \\
\text { ce plant }\end{array}$ & - & - & - & - & - & - & - & - & - & $29-48$ & - \\
\hline $\begin{array}{l}\text { (Costa et al., } \\
2001 \text { ) }\end{array}$ & $\begin{array}{l}\text { Mix of } \\
\text { plants }\end{array}$ & $68-85$ & $12-24$ & $26-29$ & $52-80$ & $75-85$ & $67-69$ & $65-68$ & - & - & $30-56$ & $28-49$ \\
\hline $\begin{array}{l}\text { (Wu et al., } \\
2016 \text { ) }\end{array}$ & $\begin{array}{l}\text { Chinese } \\
\text { network }\end{array}$ & 78 & 14.5 & 16.6 & 42.2 & 49.8 & - & - & 39.9 & 27 & - & - \\
\hline
\end{tabular}

In a few cases, estimates of the sector-wide potential savings were made based country-level statistics (Phylipsen et al., 1997; Saygin, 2012; van Ruijven et al., 2016) or specific technologies (Arens and Worrell, 2014; IEA, 2007; Milford et al., 2013). Yet, no previous study captures the full picture of resource use and RE (in exergy) of the global steel industry. Additionally, ME options such as material by-product (i.e. slag) recovery were almost always ignored. Such an analysis helps reveal the global effort required to close the true RE gap between average and best practice steel production.

To answer the questions proposed in Section 1, the most representative and up-to-date data from worldsteel is analysed. An exergy approach is used to quantify the energy and material flows both for entire routes and individual plants, and a 
metric of RE is developed to compare between plants and routes. The analysis calculates the current global average RE for each route and the plants within these, and provides estimates of technical improvement potentials (IPs) available from implementing best practice technologies. Finally, the advantages of using an exergy-based RE metric are evaluated.

\section{Methods}

Four steps are required to determine the RE of the global steel industry and the potential resource savings available: (1) the collection of global energy and material data; (2) the conversion of this data into exergy flows; (3) the definition and calculations of the RE metric; and (4) the calculation of the available resource savings from implementing best practice performance worldwide. This section describes each of these steps in turn.

\subsection{Data collection}

This study analyses energy and material flow data from 38 steel sites provided by worldsteel. These represent $9 \%$ of global crude steel production in 2010 (Gonzalez Hernandez et al., 2017) and cover the regions of: Europe, China, India, North and South America, the Middle East and the Commonwealth of Independent States. Figure 5 in the Appendix describes the number of samples analysed for each type of plant. Data is collected for two primary routes, the blast furnace-basic oxygen steelmaking route (BF-BOS) and the direct reduction-electric arc furnace (DRI-EAF), and one secondary route, the scrap-based electric arc furnace (EAF). Figure 1 shows the processes and flows for the: BF-BOS route, which converts iron ore into steel; DRI-EAF route, where directly reduced iron is fed to the furnace; EAF, where scrap is the main input. Only on-site power plants are included in our system boundary; off-site production and upstream transformation losses are excluded.

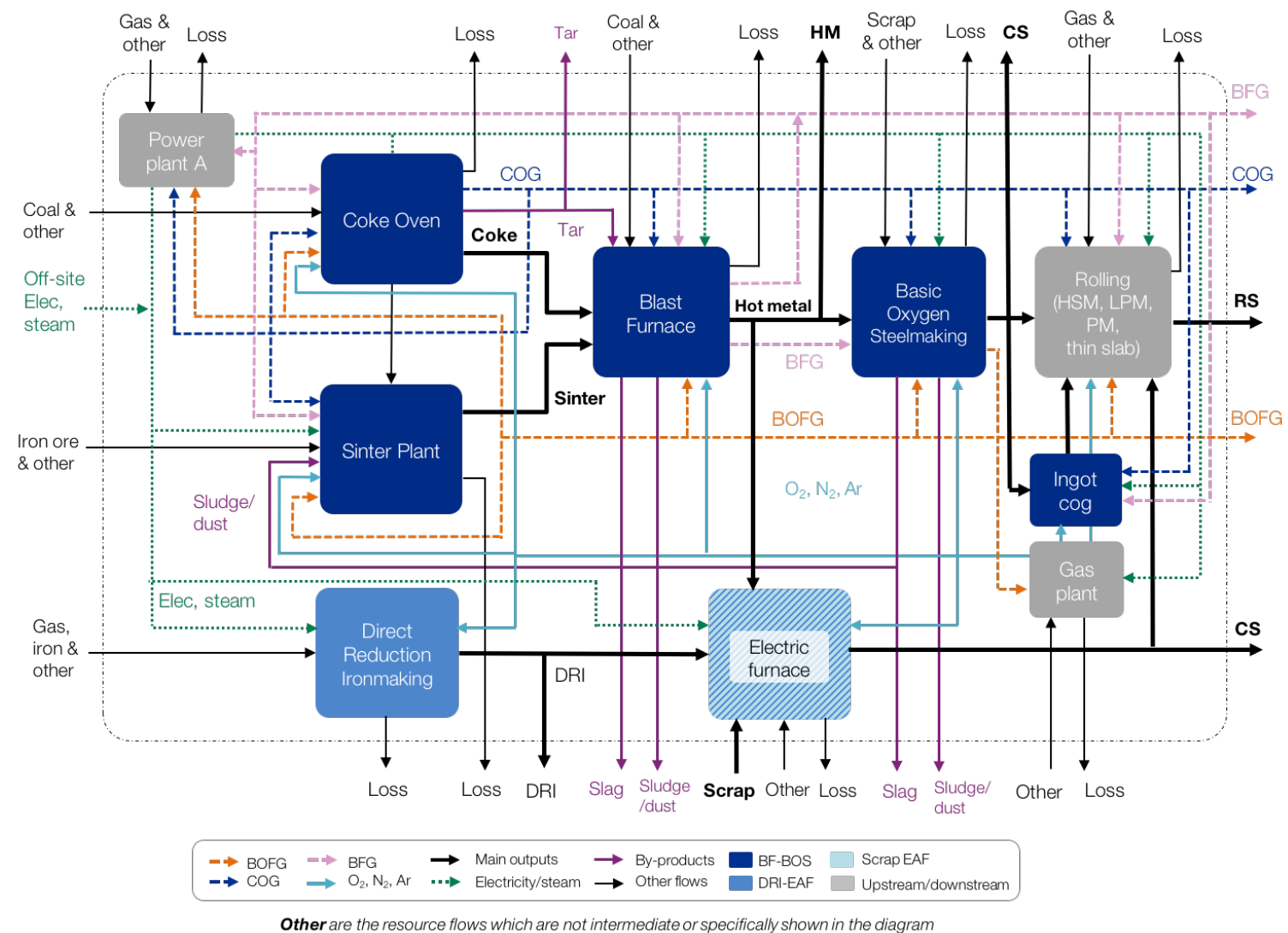

Figure 1-Schematic of the sector's processes and resource flows. Coke oven gas (COG), hot metal (HM), blast furnace gas (BFG), basic oxygen steelmaking gas (BOSG), rolled steel (RS), crude steel (CS), directly reduced iron (DRI), hot strip mill (HSM), long product mill (LPM) and plate mill (PM). 
To improve data reliability and correct for misreporting of data - mainly from misunderstandings of survey terminology or system boundaries - worldsteel use a rigorous methodology (worldsteel, 2014) with fifteen checkpoints to ensure collected data from members lies within predefined ranges. Despite these checks, misreported data can still be present. However, the remaining incorrect data is likely to result in outliers, and can therefore be ignored in the savings calculations.

\subsection{Conversion of data to exergy flows}

The most relevant contributions to the exergy flows are the chemical - resulting from a difference in the chemical composition with respect to the reference state - and physical components - resulting from a difference in the system's temperature and/or pressure with respect to the reference state. Therefore, only these two components are considered.

The chemical exergy $\left(B_{c h}\right)$ of fuels is derived from conversion factors based on low heating values (LHVs) in Nakicenovic et al. (1996), whereas the component for materials are derived from standard tables by Ayres and Ayres (1999) and Szargut (1986), as shown in Table 6 in the Appendix. Physical exergy flows $\left(B_{p h}\right)$ are calculated using the equation used by (Szargut et al., 1988), based on the temperature, pressure, and specific heat $\left(C_{p}\right)$ data for each flow. A reference temperature $\left(\mathrm{T}_{0}=25^{\circ} \mathrm{C}\right)$ and pressure $\left(\mathrm{P}_{0}=101.325 \mathrm{kPa}\right)$ are defined, with water used as a reference for liquids. The following additional assumptions are made: gases follow ideal behaviour; solids and liquids have constant $\mathrm{C}_{\mathrm{p}}$; outputs are at atmospheric pressure, except for high- and low-pressure steam (80 bar and 20 bar respectively) and blast furnace gas (BFG) at 20 bar (worldsteel, 2015). Further details on the physical exergy calculations can be found in Table 7 in the Appendix.

The exergy losses are calculated to balance the exergy inputs and outputs. These losses are often classified as: (1) external losses, including the chemical and physical exergy in waste streams, material losses (i.e. Fe yield losses), unused by-products, and emissions (i.e. $\mathrm{CO}_{2}$ ); (2) internal losses are made up of irreversibilities (i.e. entropygenerating mechanisms) from heat transfer across a finite temperature difference, combustion and chemical reactions, and the expansion and compression of fluids.

In practice, $\mathrm{Fe}$ (iron) yield losses arise in the blast furnace (BF), basic oxygen furnace (BOF) and rolling processes. These are calculated using mass balances and average Fe contents: $65 \%$ for sinter/ore/pellets; $94 \%$ for hot metal/DRI; $99 \%$ for scrap/scales/hot rolled. Yield losses in coke ovens (CO) are found by balancing average carbon (C) contents, while the calculation of chemical exergy for $\mathrm{CO}_{2}$ emissions uses mass balance and average $\mathrm{C}$ contents - see Table 8 in the Appendix. The remaining exergy losses are assumed to be irreversibilities. Information on the breakdown of irreversibilities requires equipment-level analysis in laboratory conditions. Instead, for this study, a reference plant loss breakdown from de Beer et al. (1998) is used, where irreversibilities are attributed to combustion (40\%), chemical reactions $(30 \%)$, heat transfer $(20 \%)$ and expansion/compression $(13 \%)$.

The resulting exergy flows for the entire steel industry are visualised in the form of a Sankey diagram. Here, process irreversibilities are depicted as outgoing flows and are collated at the top of the diagram. Showing these allows us to highlight the origin of most of the process losses and to provide an idea of what fraction of the losses are realistically recoverable.

\subsection{Defining a resource efficiency metric}

This study adopts the RE definition in Equation 1, where efficiency is expressed as the ratio of useful exergy outputs to total exergy inputs. Equation 1 shows the general expression for RE, where $B$ is the sum of chemical and physical exergy $\left(B_{p h}+B_{c h}\right)$, and $\left(B_{\text {mat byp }}^{\text {recovered }}+B_{\text {en byp }}^{\text {recovered }}\right)$ is the sum of the by-products recovered on-site or sold to third parties.

$$
\mathrm{RE}=\frac{\mathrm{B}_{\text {product }}^{\text {out }}+\mathrm{B}_{\text {mat byp }}^{\text {recovered }}+\mathrm{B}_{\text {en byp }}^{\text {recovered }}}{\mathrm{B}_{\text {materials }}^{\text {in }}+\mathrm{B}_{\text {energy }}^{\text {in }}}
$$

Particular care is required in deciding which flows are useful as different interpretations of usefulness can lead to different efficiency results. In this study, only the outputs further used in other processes are considered useful, for example: flared BFG is a waste, whereas BFG used to generate electricity or as a fuel is considered useful. The usefulness of the three off-gases (BFG, BOSG, COG) and the BF sludge/dust is determined by comparing the outputs to the gas or sludge fed to other processes. When data is not available, average recovery rates are assumed. For example, we assume $80 \%$ of BF and BOS slag is recovered (worldsteel, 2016) - mainly for cement/concrete 
production. Tar, benzole and oil are assumed to be fully recovered in downstream processes outside of the sector, while the BOS sludge/dust is not considered useful as this is often stockpiled on-site.

Steelmaking sites are not homogeneous and contain a variety of plant configurations. Products are frequently purchased and sold at intermediate stages, for example, some plants purchase coke to address production short fall, whereas others produce excess coke for export. To make sites comparable, mass and energy imbalances are classified as exports or imports, with individual plant exergy intensities attributed to exports and global average exergy intensities attributed to imports. Route-level analyses exclude rolling processes, as insufficient data was provided to perform a full mass balance over the entire gamut of rolling technologies (i.e. PM, LPM, HSM or thin slab rolling). Rolling processes, however, are analysed separately and included in the overall picture of the sector's resource flows.

The calculation of RE for individual plants and routes, across sites, allows distributions of RE to be graphed. RE values are grouped into bins with two or more sites to avoid revealing proprietary data for individual plants. The shape and spread of the distributions provides an insight into the potential exergy savings available in each plant and production route.

\subsection{Calculating RE savings}

Assessing the technical improvement potential of individual plants requires knowledge of: the scale of resource flow; the efficiency with which these are converted into products; and the potential efficiency improvement. The technical IP for each plant $(\Phi)$ can be expressed as the difference in resource inputs between current and target operation:

$$
\Phi=B_{\text {in }}^{\text {current }}-B_{\text {in }}^{\text {target }}
$$

Expressing this in terms of the output and efficiency, and assuming the resource output remains constant, results in:

$$
\Phi=\frac{B_{\text {out }}^{\text {current }}}{R E_{\text {current }}}-\frac{B_{\text {out }}^{\text {target }}}{R E_{\text {target }}}=B_{\text {out }}\left(\frac{1}{R E_{\text {current }}}-\frac{1}{R E_{\text {target }}}\right)=B_{\text {in }}^{\text {current }}\left(1-\frac{R E_{\text {current }}}{R E_{\text {target }}}\right)
$$

In this study, two RE targets are defined: (1) best practice, where each plant is compared to the $1^{\text {st }}$ decile plant, i.e. that representing $10 \%$ of the production volume; (2) best available, where each plant is compared to the best plant in the sample. These are both calculated assuming the technological status and resource input mix from 2010. The worldsteel resource data is considered to be representative of the global average, allowing this to be scaled up to the global level based on total steel production. This makes it possible to provide a conservative estimate of global resource use improvements available. To test the validity of this approach, Table 10 in the Appendix compares the scaled-up data and other statistics in the literature across several key parameters.

Further insight into the technical IP of the global steel industry is provided by breaking down potential resources savings into: recovery of waste gases currently flared; reductions material yield losses; recovery of unused material by-products; and capture of waste heat. Reductions in material yield losses are calculated assuming: a 5\% increase in BF yield (to 95\%); a $2 \%$ improvement in BOS yield (to 95\%); 1-2\% improvements in CO, HSM, LPM and PM yields (to $98 \%$ ).

\section{Results: global resource efficiency analysis of steel production}

This paper presents a comprehensive analysis of the RE of global steel production, using the most up-to-date and representative resource data for 2010 , and converting this to exergy to reveal opportunities for improvement. The results are presented in three parts: a global map of resource flows for the sector; a RE assessment of plants and production routes; an evaluation of the potential resource savings available at a global scale.

\subsection{Mapping resource flows}

Figure 2 shows the best estimate of global resource flows in the iron and steel sector in 2010, from coking (left) to rolling (right). Material and energy flows are presented in a Sankey diagram, where the thickness of each line represents the scale of resource flow, in units of exergy. Each node represents a plant unit and colour is used to distinguish between different types of materials and fuels. The resulting map reveals the complex interactions between energy and materials in the energy-intensive industry of steelmaking. Presenting our results in Sankey 
diagram form allows the scale of resource flows to be compared in relation to each other, providing a powerful way to highlight possible interventions and their priorisation.

The total resource input to the steel industry in 2010 is $24.7 \mathrm{GJ} / \mathrm{t}_{\mathrm{cs}}$ (gigajoules of exergy per tonne of crude steel). The BF-BOS route has an average resource input of $29.8 \mathrm{GJ} / \mathrm{t}_{\mathrm{cs}}$, whereas the DRI-EAF and the scrap-only EAF routes have values of 17.2 and $10.3 \mathrm{GJ} / \mathrm{t}_{\mathrm{cs}}$ respectively. The EAF route makes up under a third of total crude steel production, but with less than a tenth of the total exergy input. Coal contributes just under $60 \%$ of the total exergy input of all energy carriers, surpassing the inputs of electricity and natural gas. The integrated BF-BOS plants generate $36 \%$ of on-site electricity and $93 \%$ of on-site steam requirements.

Steel scrap is the largest raw material input with a value of $1.8 \mathrm{GJ} / \mathrm{t}_{\mathrm{cs}}$ (exergy). About $0.4 \mathrm{GJ} / \mathrm{t}_{\mathrm{cs}}(20 \%$ of scrap) of this is generated internally by the industry, in the BF, the BOF and in downstream rolling and fabrication processes. Surprisingly, nearly half of all of scrap $\left(0.7 \mathrm{GJ} / \mathrm{t}_{\mathrm{cs}}\right)$ is fed to the primary route (i.e. the BOS plant), contributing $10 \%$ of the exergy input and $12 \%$ of the mass of the route. Cold iron is the second largest material input; it is generated as a by-product from the BF and recycled back to the steelmaking processes: $40 \%$ to the $\mathrm{EAF}$ and $60 \%$ to the BOS.

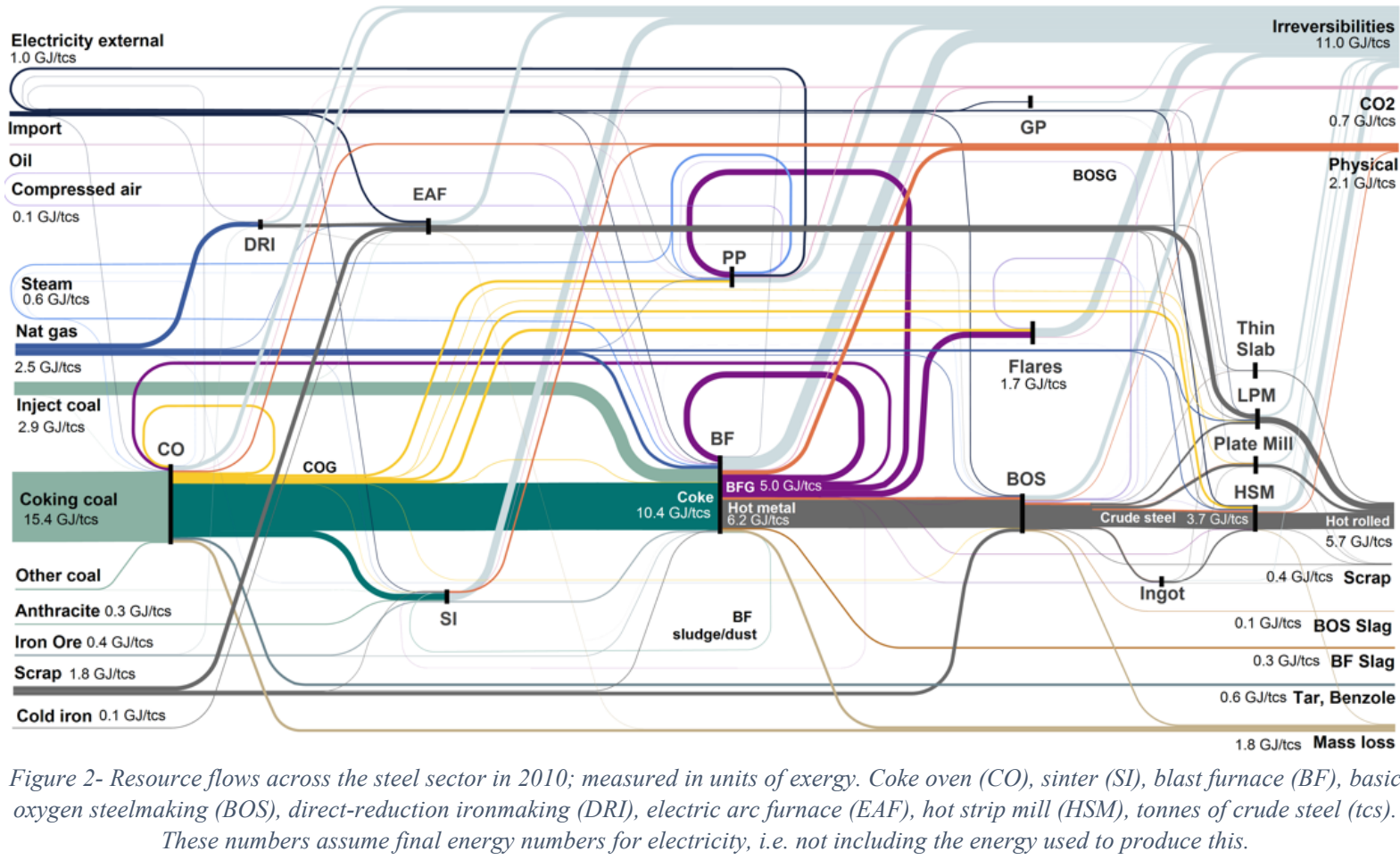

The useful outputs from global steel production consist of steel, energy by-products and material by-products. The exergy value of the steel output $\left(5.7 \mathrm{GJ} / \mathrm{t}_{\mathrm{cs}}\right)$ is equivalent to under a one-quarter of the total exergy input, giving a first indication of the RE of steel production (see Section 4.2). The largest unutilised output flows are: the flared BFG $\left(1.2 \mathrm{GJ} / \mathrm{t}_{\mathrm{cs}}\right)$; the chemical exergy $\left(0.7 \mathrm{GJ} / \mathrm{t}_{\mathrm{cs}}\right)$ of BF Fe losses; the waste heat $\left(0.5 \mathrm{GJ} / \mathrm{t}_{\mathrm{cs}}\right)$ from BFG; and the flared $\mathrm{COG}\left(0.4 \mathrm{GJ} / \mathrm{t}_{\mathrm{cs}}\right)$. These figures reveal that there is still potential to improve the recovery of the three off-gases. Only $75 \%$ BFG, $80 \%$ COG and $61 \%$ BOSG of the chemical exergy currently recovered, either as a direct fuel substitute or an input to electricity generation (they already contribute $90 \%$ of the exergy input to on-site power plants). Figure 6 in the Appendix depicts the destination of each of the waste gases. The practice of flaring off-gases wastes the equivalent of $7 \%$ of the total global exergy input to the steel sector. In total, physical exergy in the form of waste heat is lost from the BF, CO and SI. This equates to $1.4 \mathrm{GJ} / \mathrm{t}_{\mathrm{cs}}$. A full breakdown of the individual physical exergy of output flows is presented in Table 9 in the Appendix.

Failure to capture material by-products represents a significant loss of exergy. Around $0.02 \mathrm{GJ} / \mathrm{t}_{\mathrm{cs}}$ (out of $0.1 \mathrm{GJ} / \mathrm{t}_{\mathrm{cs}}$ ) of BOS slag, some $20 \mathrm{Mt}$ per year, is stockpiled. Similarly, the BF produces $0.3 \mathrm{GJ} / \mathrm{t}_{\mathrm{cs}}$ of exergy as slag, some 360 $\mathrm{Mt}$, of which about $10 \%$ is stockpiled. BF sludge/dust, $0.2 \mathrm{GJ} / \mathrm{t}_{\mathrm{cs}}$ and $28 \mathrm{Mt}$, appears to be fully recovered as feedstock in sinter plants, whereas close to $2 \mathrm{Mt}$ of BOS sludge/dust is thought to be stockpiled. Attempts to recover BOS sludge/dust have proved challenging due to the high Zinc contents (Trung et al., 2011). A total of $1.8 \mathrm{GJ} / \mathrm{t}_{\mathrm{cs}}$ of material exergy losses result from upstream production, however most material lost from the BF, BOS, EAF and rolling 
processes is thought to be recirculated internally. Table 11 in the Appendix provides a loss breakdown for each process.

Irreversibilities, i.e. internal losses, sum to $11.0 \mathrm{GJ} / \mathrm{t}_{\mathrm{cs}}$ with $4.0 \mathrm{GJ} / \mathrm{t}_{\mathrm{cs}}$ lost in combustion, $3.2 \mathrm{GJ} / \mathrm{t}_{\mathrm{cs}}$ in chemical reactions, $2.3 \mathrm{GJ} / \mathrm{t}_{\mathrm{cs}}$ in heat transfer mechanisms and $1.4 \mathrm{GJ} / \mathrm{t}_{\mathrm{cs}}$ in expansion and compression. The largest share of irreversibilities is associated with combustion processes and chemical reactions, which are difficult to avoid without the need to redesign of the process. However, heat transfer and expansion/compression losses can be reduced through improved component design and modifying temperature profiles.

\subsection{Resource efficiency of individual plants and production routes}

Table 2 summarises the energy intensity (EI), exergy intensity (ExI) and RE results for the three steelmaking routes and the nine individual plants. The overall ExI and RE of the global steel sector are $24.7 \mathrm{GJ} / \mathrm{t}_{\mathrm{cs}}$ and $32.9 \%$ respectively, including all three steelmaking routes and with the addition of the rolling processes. The BF-BOS route is shown to be the least efficient route, with an average RE of $29.1 \%$, which is less than half the efficiency of the scrap-based EAF route at $65.7 \%$. However, the BF-BOS route involves the more complex reduction of iron-ore to steel. On its own, the BF plant $(64.6 \%)$ is more resource-efficient than the EAF plant $(62.5 \%)$ - considering the utilisation of most of the BFG, also rivalling the most efficient combustion technologies available (i.e. diesel engines, gas turbines). However, once upstream coking and sintering plants, and downstream steelmaking (BOS) are included, the combined RE is reduced to $29.1 \%$.

Table 2-Energy intensities, exergy intensities and resource efficiencies (average, maximum and minimum) for individual plants and production routes. Routes do not include the rolling plants. Electricity production is not included in these figures.

\begin{tabular}{llcccccccccc}
\hline & & \multicolumn{3}{c}{ EI (GJ/t of product) } & \multicolumn{2}{c}{ ExI (GJ/t of product) } & \multicolumn{3}{c}{ RE (\%) } \\
\hline Plant & Product & Avg. & Min. & Max. & Avg. & Min. & Max. & Avg. & Min. & Max. \\
\hline CO & coke & 8.0 & 5.0 & 12.1 & 8.2 & 7.2 & 12.0 & 85.3 & 78.1 & 90.7 \\
SI & sinter & 2.0 & 1.2 & 2.8 & 2.5 & 1.7 & 3.6 & 10.8 & 7.7 & 14.8 \\
BF & hot metal & 14.7 & 11.6 & 21.8 & 21.4 & 18.7 & 26.3 & 64.6 & 50.5 & 81.8 \\
DRI & DRI & 11.9 & 11.0 & 13.6 & 12.9 & 11.6 & 14.6 & 62.2 & 54.4 & 68.6 \\
BOS & & 0.2 & -0.4 & 1.9 & 9.4 & 8.8 & 10.7 & 80.2 & 64.2 & 93.1 \\
EAF & \multirow{2}{*}{ crude steel } & 2.7 & 2.0 & 3.9 & 10.9 & 9.4 & 13.0 & 62.5 & 52.7 & 75.0 \\
HSM & & 1.6 & 0.4 & 2.0 & 8.6 & 7.4 & 9.2 & 80.5 & 76.5 & 91.0 \\
PM & & 2.8 & 1.6 & 5.3 & 10.4 & 9.2 & 13.2 & 73.1 & 61.6 & 81.2 \\
LPM & & 2.5 & 0.3 & 5.9 & 9.6 & 7.1 & 13.0 & 77.3 & 55.6 & 94.8 \\
\hline BF-BOS route & & 26.3 & 20.5 & 33.0 & 29.8 & 25.3 & 37.7 & 29.1 & 23.1 & 33.0 \\
DRI-EAF route & \multirow{2}{*}{ crude steel } & 11.2 & 4.2 & 16.3 & 17.2 & 12.5 & 23.4 & 40.5 & 28.9 & 54.1 \\
Scrap-EAF route & & 2.8 & 2.1 & 3.8 & 10.3 & 9.7 & 12.0 & 65.7 & 56.4 & 69.6 \\
\hline Global industry & crude steel & 22.6 & - & - & 24.7 & - & - & 32.9 & - & - \\
\hline
\end{tabular}

The granularity of the data collected makes it possible to go beyond simple efficiency averages and min/max ranges, to characterise RE distributions for plants and production routes (Section 4.2.5). Figure 3 shows the variability of RE for individual plants, weighted by production volume. The shape of most distributions varies across plants and are either bi-modal or skewed. This results from the use of different technologies, the varying amount of by-products recovered, differences in operational practices, and the potential randomness ensued by only including a limited number of sites. The following sections describe each of the efficiency distributions in more detail. 

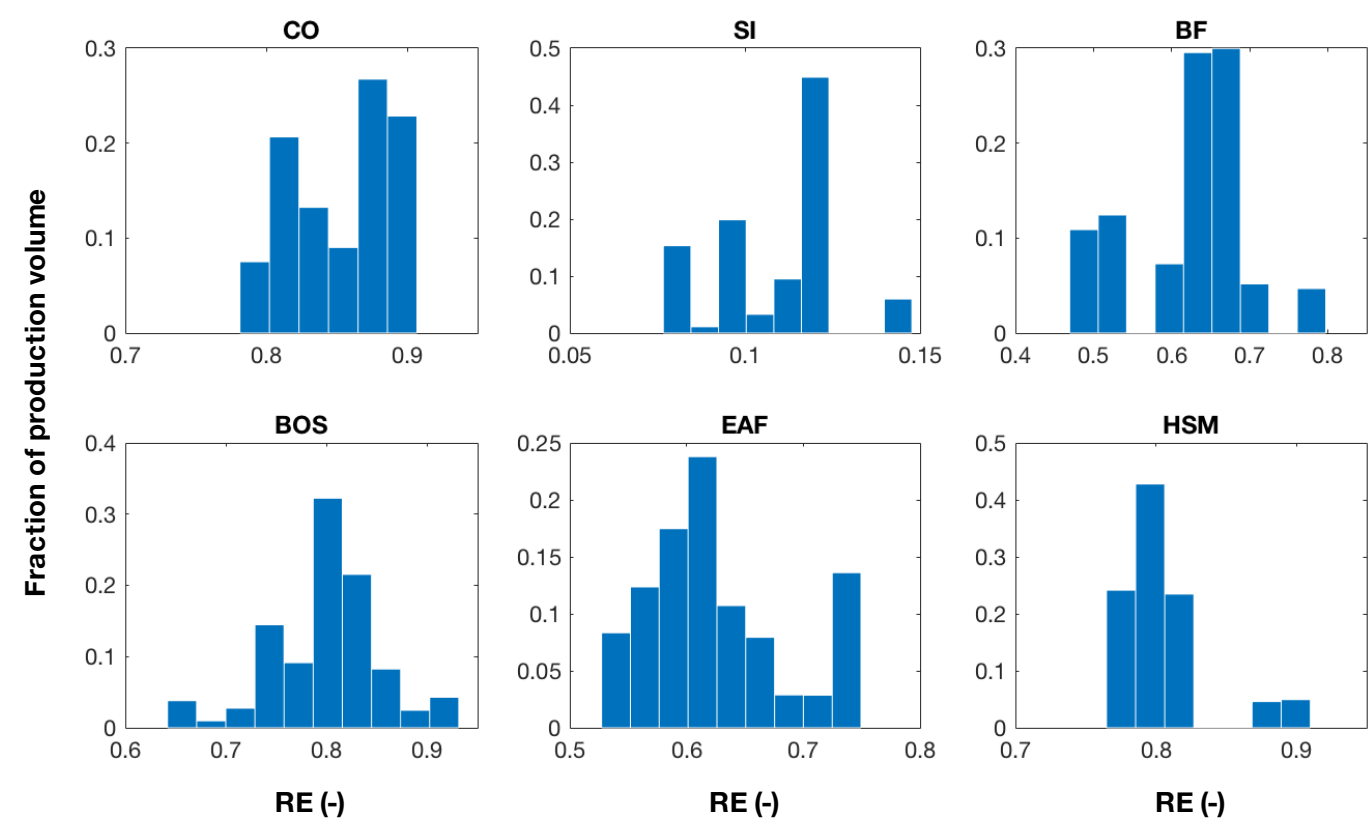

Figure 3-Distributions of resource efficiencies (-) for six plants: coke oven (CO), sinter (SI), BF, BOS, EAF and hot strip mill (HSM). The DRI, ingot, plate and thin slab are not portrayed because the small number of plants compromises confidentiality.

\subsubsection{Coking and sintering}

The $\mathrm{CO}$ and SI plants exhibit the narrowest distributions (ranges of $13 \%$ and $7 \%$ ). The $\mathrm{CO}$ has a narrow RE range (78-91\%) which can be explained by the similarity in high-value fuel inputs and the consistent recovery of material by-products (tar and benzole) and COG (80\% with a standard deviation of 36\%) across the sites. The bi-modal distribution is thought to arise from technology differences, particularly the implementation of coke-dry-quenching, found only at some sites. Improving the recovery of $\mathrm{COG}$ and steam present the best options for tightening this small RE gap in CO plants.

\subsubsection{Blast and electric furnaces}

In contrast, the $\mathrm{BF}$ and $\mathrm{EAF}$ have wider distributions, with ranges of $31 \%$ and $22 \%$ respectively. For both types of furnaces, the distribution appears to have a bi-modal shape. In the BF, the variation in RE results from two factors. First, the inherent flexibility of the process, which can use a wide range of fuels. Second, the large number of technologies available for improvements, the different combinations of which cause varying levels of RE. The main improvement technologies include: the injection of pulverised coal or other injectants, such as tar or natural gas; the adoption of combustion monitoring and controlling systems; the installation of top recovery turbines; and the recovery of BFG for further use as a fuel. From these, the largest RE variations arise from the implementation of topgas recovery and the recovery of BFG (standard deviation of $22 \%$ ). Currently, the amount of BFG recovered, and the electricity produced and consumed in BFs varies substantially across plants.

The EAF shows a wide range of REs and a bi-modal shape. This results from the DRI-to-scrap input ratio, where the peak at the high-end $(\sim 74 \%)$ is scrap-based EAF plants, and at the low-end $(\sim 62 \%)$ is the DRI fed EAF plants. Combined with these differences in burden types, there are three other factors causing the variation in RE: the existence of multiple melting practices worldwide; the wide range of EAF types and differences in the fuel inputs. The main technologies relevant to the operation of EAFs are: improved monitoring and control (mainly for electricity and gas); improved flue gas monitoring; scrap preheating or bottom stirring.

\subsubsection{Basic oxygen furnaces}

The BOS plant, shows a symmetrical distribution which is close to normal. The wide variation in BOS RE, nearly $30 \%$ can result from three main factors: the percentage of BOSG recovered; the ratio of scrap-to-hot metal input; differences in the waiting times between batches (and therefore in the fuel consumption of pre-heating). In particular, the recovery of BOSG averages $61 \%$ with a standard deviation of $46 \%$, which is the largest variation of the three off- 
gases. The most relevant improvement options available to BOS plants include, namely the recovery of BOF dust/sludge, the improvement in the calorific value of the BOSG recovered through better management of ladle lids, and the increase in the ratio of scrap input.

\subsubsection{Hot-strip mills (HSMs)}

In HSMs the small variation across sites results from: the consistently high heat recovery rates for the reheating furnaces; low levels of electricity consumption in part from the widespread implementation of advanced control systems; the relatively uniform size of the rolling mills across sites. The dataset reveals a few highly-efficient plants (at about 90\%), which result from the reporting of low electricity inputs. These low electricity inputs result from the fact that only a small number of the plants in the dataset have implemented a large number of improvement measures (over 18). Some of these improvement technologies include: air-to-fuel ratio controls to improve combustion efficiency; the preheating of air; the recovery of heat from waste gases; the use of regenerative burners; hot charging and the use of walking beam furnaces.

\subsubsection{Production routes}

Figure 4 portrays the RE distributions for the three steelmaking routes. These show that heterogeneity exists in all three, indicating there is still technical potential for improvement. The BF-BOS route has a uniform distribution with three peaks in efficiency, ranging from $20.5 \%$ to $33.0 \%$. Despite the wide distributions observed in the REs of the $\mathrm{BF}$ and BOS processes, the BF-BOS route shows a relatively narrow RE range. This emphasises that benchmarking entire routes can provide a more realistic understanding than benchmarking individual plants - as is often performed - as it is unlikely that a given site contains all the most efficient plants. The small RE variations that do exist mainly result from the implementation of coke-dry quenching, off-gas recovery systems or hot-connect between the BOS plant and the HSM. Although independent of plant size, variations also arise from differences in the proportions of imports/exports of intermediate products for each site.

The DRI-EAF route shows a normal-like distribution and has a greater range in RE compared to the other two routes. This arises from three differences: the shares of metal inputs, i.e. the DRI-to-scrap ratio for each site; the types of technologies (e.g. HyL III versus MIDREX ${ }^{\circledR}$ process); and the degree to which fuel-utilisation measures are installed. This ratio of iron inputs is known to have a significant effect on the energy intensity of the EAF process with higher fractions of scrap resulting in greater efficiencies (worldsteel, 2014). The scrap-EAF route shows a positively skewed distribution, suggesting a smaller gap for incremental improvement.
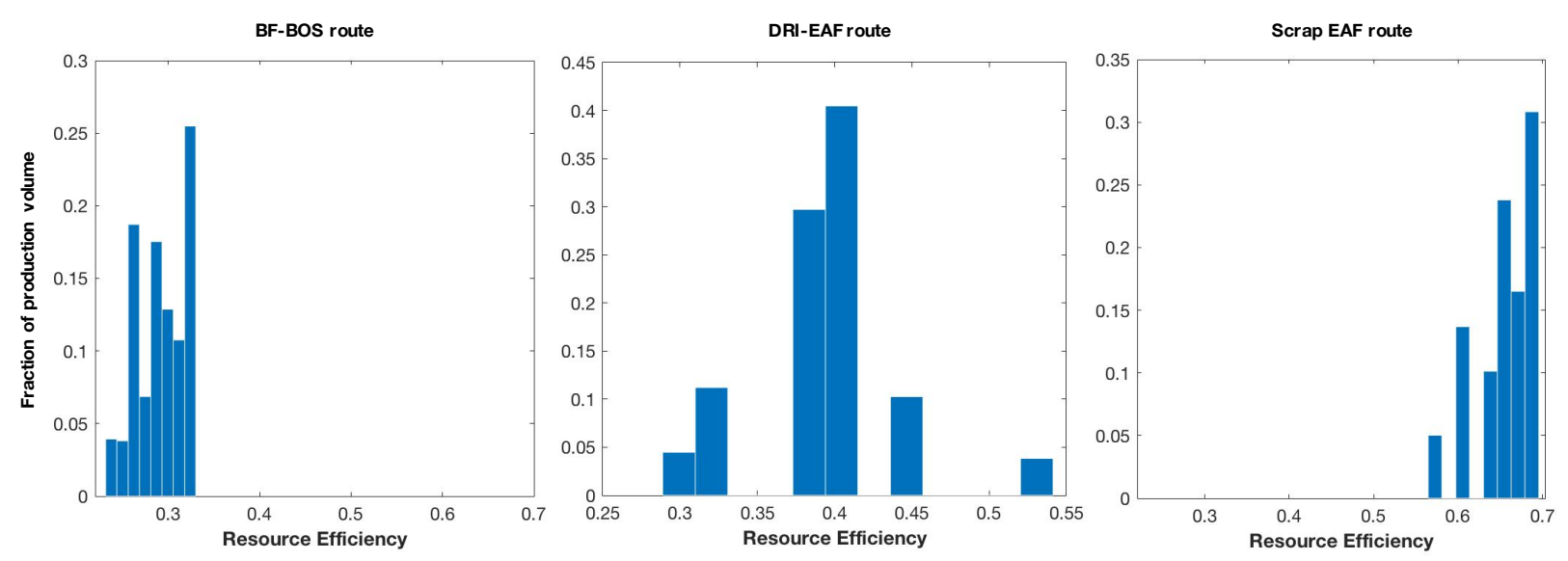

Figure 4-Distributions of RE across the three production routes.

\subsection{Potential resource savings}

Table 3 summarises the resource savings (in exergy) available from making individual improvements to plants, and from moving to best practice and best available operations. Three key opportunities for reducing exergy resource inputs are introduced: recovering flared off-gases and material by-products; moving to best available operation; shifting from ore-based to scrap-based production. Plant- and route-level values are different because rolling is not included in the routes. 
Table 3-Summary of global resource savings available in the steel industry. This table is subject to rounding errors.

\begin{tabular}{ccccccc}
\hline & \multicolumn{3}{c}{ Individual improvement options (EJ of exergy/yr) } & \multicolumn{2}{c}{ Best Practice (Best Available) } \\
\hline \multirow{2}{*}{ Plant } & $\begin{array}{c}\text { Waste gas } \\
\text { recovery }\end{array}$ & $\begin{array}{c}\text { Waste heat } \\
\text { recovery }\end{array}$ & $\begin{array}{c}\text { Material by- } \\
\text { product recovery }\end{array}$ & $\begin{array}{c}\text { Yield loss } \\
\text { (direct) }\end{array}$ & $\begin{array}{c}\text { IEA (IEA, 2007) } \\
\text { (EJ of energy/yr) }\end{array}$ & $\begin{array}{c}\text { This study } \\
\text { (EJ of exergy/yr) }\end{array}$ \\
\hline CO & 0.4 & 0.2 & - & 0.1 & $0.4(0.6)$ & $0.9(1.1)$ \\
SI & - & 0.3 & - & - & - & $0.2(0.9)$ \\
BF & 1.2 & 0.7 & 0.04 & 0.4 & $1.2(1.5)$ & $2.0(4.5)$ \\
DRI & - & - & - & - & - & 0.1 \\
EAF & - & 0.2 & 0.01 & 0.1 & 0.25 & $0.1(0.5)$ \\
BOS & 0.1 & 0.7 & 0.03 & 0.1 & 0.25 & $0.6(1.3)$ \\
Rolling & - & 0.3 & - & 0.1 & $0.3(0.4)$ & $0.5(1.3)$ \\
\hline Total & 1.7 & 2.4 & 0.09 & 0.8 & & 4.4 \\
\hline BF-BOS & 1.7 & 2.0 & 0.07 & 0.7 & - & $3.4(4.1)$ \\
DRI-EAF & - & 0.1 & 0.01 & 0.1 & - & $0.5(2.3)$ \\
Scrap EAF & - & 0.1 & 0.01 & 0.1 & - & 0.0 \\
\hline Total & 1.7 & 2.2 & 0.09 & 0.9 & $2.3-2.9$ & $3.9(6.4)$ \\
\hline
\end{tabular}

The current practice of flaring off-gases results in the loss of 1.7 EJ of exergy: 1.2 EJ of BFG, 0.4 EJ of COG and $0.1 \mathrm{EJ}$ of BOSG. A maximum of $2.2 \mathrm{EJ} / \mathrm{yr}$ of waste heat could be recovered globally, an amount which is greater than the final energy use of the EU28 steel industry in 2015. From this 2.2 EJ, up to 1.8 EJ is available from solids such as slags, crude steel, coke and sinter. Recovering heat from solids is more challenging than from gases or liquids, however, recent technology advances have made commercial recovery a reality for slag (Zhang et al., 2013), coke, and sinter (Carpenter, 2012). Exploiting this technical potential requires policy intervention, as current return on investment rates are too low to drive take-up for most European companies (Banerjee et al., 2012). Similarly, fully recovering waste gases requires substantial site-level modifications and large investments in infrastructure to install new piping and gas holders.

Moving from current to best available operation in primary production can save up to $6.4 \mathrm{EJ} / \mathrm{yr}$ globally, equal to about $25 \%$ of the sector's total exergy input and $40 \%$ of the total primary energy input to EU (28) industry in 2015 (Eurostat, 2016). The largest fraction of this improvement comes from the BF-BOS route, as this is the most energy intensive of the three. Within this route, the BF plant yields the largest energy savings, through improved operational excellence, alongside increased recovery rates of BFG, slag, and sludge/dust, and reductions in $\mathrm{coal} /$ coke inputs. In the BF-BOS route, reducing $\mathrm{Fe}$ yield losses can save up to $0.8 \mathrm{EJ} /$ year; later stages of production should be prioritised as these save an increasing amount of embodied upstream exergy losses.

A shift from ore-based to scrap-based production is key for reducing resource use and mitigating emissions in the steel industry. Currently, scrap-based EAF consumes one-third of the exergy required for BF-BOS, and is more than twice as resource efficient. Assuming steel demand doubles 2050 (Waugh, 2013) and scrap steel from recycling accounts for half of all demand (limited by available scrap for recycling) (Pauliuk et al., 2013), then switching from ore-based to scrap-based production could result in almost $8 \mathrm{EJ}$ in exergy input savings. This shift does not necessarily mean the demise of the BF-BOS route, as this can accept up to $30 \%$ scrap input, and currently $44 \%$ of the global scrap is melted in BOS plants. In addition, in 2050 half of all steel demand is still expected to come from ore-based production (Pauliuk et al., 2013), so any shift towards secondary production still needs to be accompanied by parallel exergy savings in the BF-BOS - pushing towards best available operation.

\section{Discussion}

Global steel production has an overall RE of $32.9 \%$. By shifting to best available operation, up to 6.4 EJ could be saved globally in the steel sector per year, including 1.7 EJ alone from the flaring of off-gases. Most of these savings come from improvements in the primary production route. Under aggressive assumptions, namely fully preventing the flares of BFG, COG and BOSG, recovering material yield losses, and utilising the available material by-products, the RE can increase to above $40 \%$; recovering all wasted heat pushes this up to $45 \%$. This section compares the results of this study with previous studies and discusses the implications of the results presented.

\subsection{How do these values compare to previous studies?}


This paper defines RE based on exergy, and applies this approach to nine types of plants and three routes, to deliver the most up-to-date and comprehensive exergy analysis of the global steel industry. This section compares the results obtained in this study with other analyses found in the literature: firstly, the RE results are compared to those from literature in Table 1; secondly, the calculated resource savings are compared to those in the IEA (2007) report.

Many studies of the BF fail to consider the recovery of BFG as a useful output, counting only the pig iron. For this reason, the RE of $64.6 \%$ for the $\mathrm{BF}$ is much higher than the $42.2 \%$ quoted for the Chinese network (Wu et al., 2016), although it still lies within the 52-80\% range reported by Costa et al. (2001). The RE for sintering (10.8\%) is lower than many of the values quoted in the literature (12-24\%), except for $4.3 \%$ quoted by Ayres et al. (1996). These large variations are thought to result from the varying amounts of waste heat recovered across different sites. The RE for the EAF reported by Costa et al. (2001) (67-69\%) lies within the range calculated here, 52.7-75\%, however the calculated average $62.5 \%$ is much lower. (J Szargut et al., 1988) reported an even lower value of $52.2 \%$. The discrepancies observed in RE for EAF result from the different shares of iron inputs used. In this study, these range from $100 \%$ scrap to $100 \%$ DRI input.

The average RE of the BF-BOS route is $29.1 \%$, less than that reported by Costa et al. (2001), de Beer et al. (1998) and Ayres et al. (1996). There are two reasons why the RE reported by Ayres et al. (1996) for the US in 1988 is higher than today's average: the shares of primary and secondary production for the US in 1988 were $53 \%$ to $47 \%$, a lot higher than today's global average; and most of the iron ore was pelletised rather than made into sinter, the latter having a lower efficiency than the former. Costa et al. (2001) and de Beer et al. (1998) use indicative and reference data respectively, and these plants therefore have higher efficiencies. The RE for the DRI-EAF route (29-54\%) calculated in this study lie within those reported by Costa et al. (2001), although these are not directly comparable as Costa et al. (2001) based their analysis on a single DRI technology, COREX.

In 2008, in their last detailed study on industrial energy and emissions, the IEA (2007) predicted that 2.9 EJ of primary energy could be saved by shifting current primary production to best practice technologies, while an extra 2.1 EJ could be saved by increasing the use of recycled steel. Our analysis estimates greater potential savings (6.4 $\mathrm{EJ} / \mathrm{yr}$ ) for two reasons. First, the IEA neglects the savings from the sinter plant and the BFG recovery, which are included here. Second, our study includes ME options, (mainly in the BF, BOS and rolling), such as yield improvements or the recovery of material by-products. The value of flared COG reported by the IEA (2007) for China in 2005 (250 PJ) corresponds to about $60 \%$ of the value calculated in this study (430 PJ); percentage which is comparable to the fraction of global pig iron produced in China.

\subsection{Exergy as a tool to measure resource efficiency in industry}

Measuring RE in exergy units makes it possible to define a single, dimensionless metric that is able to capture both energy and material flows. This metric is dimensionless and therefore allows comparisons across different processes producing different products. For example, it is possible to compare the RE of a copper furnace and a steel blast furnace. Resource efficiency, measured in exergy units, is usable at different system levels, from process, through to plant, firm or regional-level. It captures both the first and second laws of thermodynamics and therefore reveals the irreversibilities in real processes and the quality of resource flows, including both chemical and physical properties. Understanding the irreversibilities generated in production plants can guide efforts to improve technology designs.

The quality of the data used in this analysis delivers improvements in the accuracy of RE calculations for the steel industry. For the first time, representative RE distributions are presented for plants and production routes. Unlike in previous studies, where it is assumed that by-products are fully recovered, this study defines RE in a way that accounts for the by-products actually used. Armed with improved data, it is possible to use the RE metric to benchmark across different plants in the sector. As a result of this study, worldsteel is using exergy to compare the RE performance of individual plants to a reference plant, providing insights into potential resource reductions. This fills a clear knowledge gap, where there is a lack of an internationally-agreed benchmarking approach to compare steelmaking plants and production routes (IEA, 2007).

Conventionally, energy analyses of the steel sector tell us that ore-based production is twice as energy-intensive as scrap-based steelmaking. Our RE analysis, goes a step further, and reveals that the scrap-EAF route is more than twice as resource-efficient as ore-based steelmaking. The proposed exergy-based RE metric therefore provides an additional incentive for shifting to EAF recycling. Given the limited scrap availability in the future and its quality and contamination issues (Daehn et al., 2017), however, a shift to more scrap-based production will need to be supplemented with the implementation of best practices in the BF-BOS route. 
The value of exergy as a RE indicator for bulk materials (e.g. low-alloyed steels) is clear and has been advocated for by many academics such as (Ayres et al., 2011; Masini and Ayres, 1996; Jan Szargut et al., 1988). Yet, exergy is not always a good reflection of the value of final products, especially in down-stream processes producing specialised steels or steel-intensive manufacturing sectors. Here exergy-based RE metrics should be complemented with lifecycle type metrics that include the upstream energy and emissions embodied in these energy-intensive.

\subsection{Resource efficiency in EU and global policy-making}

Globally, more action is required to promote the implementation of ME measures as ways of reducing energy and emissions in heavy industries. Some initial progress has been made, with many countries supporting material efficiency policies to encourage recycling. However, models which assess the effect of recycling on EE targets are only just beginning to emerge. For example, the (IEA, 2015a) includes a material efficiency scenario (pp. 409-423) covering five energy intensive industries (aluminium, paper, plastics, cement and steel). For steel, the ME scenario result in a $21 \%$ reduction in energy demand in 2040 , corresponding to a reduction of almost a fifth compared to today.

Today, the EU is committed to achieve at least $27 \%$ reduction in primary energy consumption by 2030 . Recovering available exergy in unutilised material by-products and material losses could be a key strategy for achieving this. The Energy Efficiency directive resists specifying the methods through which these energy savings are achieved. Yet, the lack of recognition given to ME options within the energy policy narrative, means that ME is rarely included the Member State National Energy Efficiency Action Plans and energy-reduction portfolios (European Commission, 2015).

RE metrics can also support policies on resources. The EU has developed metrics within the circular economy (CE) and the RE policy portfolios, namely the RE Scoreboard, the CE Monitoring Framework and the Organisation Environmental Footprints project (Humphris-Bach et al., 2015). Yet none of these schemes contain metrics designed to help energy-intensive material producers quantify their level of RE or 'circularity'. The metrics included are instead mostly macro-economic (e.g. resource productivity, or emissions per capita) or targeted at downstream consumers (e.g. $\mathrm{tCO}_{2} / \mathrm{t}$ of product). It is our view that to be useful, a metric must encourage the adoption of EE and $\mathrm{ME}$, and reveal the underlying causes of resource loss. An RE metric measured in exergy enables energy- and material-saving options to be analysed jointly.

\subsection{Limitations}

The following limitations were identified for this study: (1) the data from worldsteel, although carefully selected to be representative of the global picture, still only covers $9 \%$ of global steel production. Data from large steel producers with growing economics, for example China and India, may be underrepresented; (2) reported plant data is not always complete, with data sometimes unavailable for: composition, temperature and pressure of resource flows; material yields; amount of material by-products; fraction of by-products used elsewhere. In these cases, average values extracted from other plants, must be used to fill in the gaps leading to increased uncertainty; (3) the calculated resource savings represent upper limits for each process, as they assume: all waste heat can be recovered and highlevels of material by-product recovery.

\section{Conclusions}

This global analysis of RE in the steel industry offers four main contributions to the literature, it provides:

- the most recent and comprehensive data of energy and material use in the global steel industry, including RE distributions for individual plants and production routes

- the most recent analysis of resource use and RE of the sector

- the first comprehensive comparison of current average exergy-based RE with best practice and best available operations for the global steel industry

- a holistic resource analysis that considers both energy and material efficiency improvement options side by side.

Our results show that the recovery of waste gases, waste heat and material yield losses provide the largest contributions to the overall resource savings. The resource savings available from the recovery of waste gases (1.7 EJ) and of waste heat (2.2 EJ) are significant; each is larger than the total final energy input to the EU (28) iron and steel sector in 2015 (2.1 EJ). Moving to best practice or best available operation in all steel production routes yields 
direct exergy savings of 3.9 EJ or 6.4 EJ per year, respectively. This system-level analysis is a step towards understanding the interactions of resource flows and plant efficiencies of industry, and therefore is an appropriate tool for industry practitioners and policy makers to monitor and benchmark the RE of the steel industry.

\section{Acknowledgements}

This research is funded by Emerson Electric co. This study was supported by worldsteel. We thank the team at worldsteel, especially Henk Reimink, Rizwan Janjua and Jay Choi, who provided insight and expertise that assisted the research.

\section{A. Appendix}

This appendix includes data relevant to the methods and result sections of this paper.

Table 4 includes all the abbreviations used throughout this paper.

Table 4-Abbreviations

\begin{tabular}{llll}
\hline Abbreviation & Description & Abbreviation & Description \\
\hline BF & Blast furnace & EU & European Union \\
BFG & Blast furnace gas & EJ & Exajoules \\
BOF & Basic oxygen furnace & GJ & Gigajoules \\
BOS & Basic oxygen steelmaking & HSM & Hot strip mill \\
BOSG & Basic oxygen steelmaking gas & IEA & International Energy Agency \\
CE & Circular economy & IP & Improvement potential \\
CO & Coke oven & ME & Material efficiency \\
COG & Coke oven gas & LHV & Low heating value \\
CS & Crude steel & LPM & Long-product mill \\
DRI & Direct reduction ironmaking & SI & Sinter \\
EAF & Electric arc furnace & PM & Plate mill \\
EE & Energy efficiency & RE & Resource efficiency \\
EEI & Energy efficiency index & RS & Rolled steel \\
\hline
\end{tabular}

Figure 5 depicts the number of samples analysed for each of the plants (as reported by worldsteel).

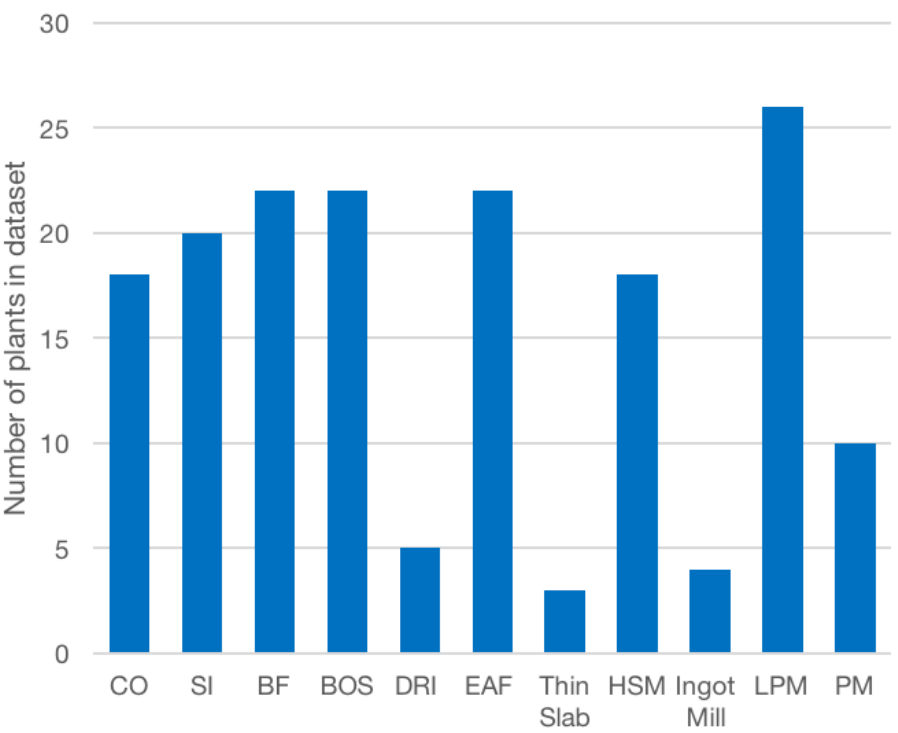

Figure 5- Number of samples analysed for each individual plant in the data set

Table 5 summarises the chemical exergy values of selected materials used this analysis. 
Table 5-Chemical exergy of selected materials used in the steel industry

\begin{tabular}{lcl}
\hline Materials & Value $(\mathrm{GJ} / \mathrm{t})$ & Source \\
\hline Pig iron & 8.0 & Taken from (Szargut and \\
DRI, Steel & 6.8 & Egzergia, 2007) \\
Oxygen & 0.1 & \\
Nitrogen & 0.03 & \\
Carbon dioxide & 0.44 & \\
\hline Iron ore & 0.4 & Taken from (Ayres and Ayres, \\
Pellets & 0.2 & $1999)$ \\
Sinter & 0.3 & \\
BF slag & 1.2 & \\
Coke & 33.9 & \\
Coal tar & 37.1 & \\
Limestone & 0.05 & \\
Dolomite & 0.2 & \\
Flue dust & 25.9 & \\
\hline BFG & 2.7 & Calculated from worldsteel \\
COG & 38.7 & composition and values for \\
BOSG & 6.6 & elements in (Szargut and Egzergia, \\
BOF slag & 1.5 & 2007) \\
\hline
\end{tabular}

The conversion factor $(f)$ for the average composition of coal (1.06) was used for all the coal types including, BF injection coal, coking coal, anthracite and EAF coal. Similarly, the $f$ for crude oil (1.04) was used for both heavy and light oils, and "other gas" was converted using the $f$ for natural gas (1.03). The following assumption is made, adopted from Ayres et al. (1996) (Masini and Ayres, 1996): "the three main sinks - atmosphere, oceans and crust -... the reaction products in any given case must go to one of the three, depending on whether they are volatile (to air), soluble in water (to oceans) or neither (to earth's crust)". Table 6 summarises the density and LHVs for the three off-gases using worldsteel data (worldsteel, 2015).

Table 6- LHV and density of the industrial off-gases

\begin{tabular}{ccc}
\hline Off-gas & LHV $(\mathrm{MJ} / \mathrm{kg})$ & Density $(\mathrm{kg} / \mathrm{m} 3)$ \\
\hline COG & 41.56 & 0.46 \\
BOSG & 6.69 & 1.26 \\
BFG & 2.44 & 1.35 \\
\hline
\end{tabular}

Table 7 depicts the values used in the calculations of the physical exergy of the resource streams.

Table 7- Calculations for physical exergy of a selection of resources. Atmospheric pressure is assumed to be $101.3 \mathrm{kPa}$.

\begin{tabular}{|c|c|c|c|c|c|}
\hline Resource & $\begin{array}{l}\mathrm{Cp} \\
(\mathrm{kJ} / \mathrm{kgK})\end{array}$ & $\begin{array}{l}\text { Temp. } \\
\left({ }^{\circ} \mathrm{C}\right)\end{array}$ & $\begin{array}{l}\text { Pressure } \\
(\mathrm{kPa})\end{array}$ & $\begin{array}{l}\text { Physical } \\
\text { Exergy }(\mathrm{GJ} / \mathrm{t})\end{array}$ & $\begin{array}{l}\text { Sources (Data on temperature provided by } \\
\text { (Worldsteel, 2015a)) }\end{array}$ \\
\hline BOSG & 0.93 & 1200 & 101.3 & 0.65 & Data on gas composition by (worldsteel, 2015) \\
\hline COG & 3.05 & 500 & 101.3 & 1.20 & Data on gas composition by (worldsteel, 2015) \\
\hline $\mathrm{BFG}$ & 0.99 & 350 & 200 & 0.35 & Data on gas composition by (worldsteel, 2015) \\
\hline BF, BOS slag & 1.35 & 1200 & 101.3 & 0.94 & $\mathrm{C}_{\mathrm{p}}$ provided by (Monaghan and Brooks, 2002) \\
\hline HP steam & 2.48 & 500 & 8000 & 1.35 & Pressure provided by (worldsteel, 2015) \\
\hline LP steam & 2.35 & 300 & 2000 & 0.75 & Pressure provided by (worldsteel, 2015) \\
\hline Hot Metal & 0.68 & 1300 & 101.3 & 0.53 & $\mathrm{C}_{\mathrm{p}}$ provided by (Lally et al., 1990) \\
\hline Liquid Steel & 0.71 & 1300 & 101.3 & 0.55 & $\begin{array}{l}\mathrm{C}_{\mathrm{p}} \text { provided by (Lally et al., 1990; Spittel and } \\
\text { Spittel, 2009) }\end{array}$ \\
\hline Hot Rolled & 0.63 & 900 & 101.3 & 0.55 & $\mathrm{C}_{\mathrm{p}}$ provided by (Lally et al., 1990) \\
\hline Coke & 1.26 & 800 & 101.3 & 0.70 & $\begin{array}{l}C_{p} \text { provided by (Loison et al., 1989); temperature } \\
\text { from (de Beer et al., 1998) }\end{array}$ \\
\hline Sinter & 0.92 & 700 & 101.3 & 0.25 & $\begin{array}{l}\mathrm{C}_{\mathrm{p}} \text { provided by (Tian et al., 2015), and taken as } \\
\text { that at a temperature of } 1173 \mathrm{~K}\end{array}$ \\
\hline
\end{tabular}


Global average carbon contents were obtained from a series of references, as summarised in Table $8{ }^{1}$. $\mathrm{CO}_{2}$ emissions released during the upstream production of e.g. electricity, steam or oxygen are not embodied onto the streams. Only the carbon contained in materials and fuels are considered.

Table 8-Carbon contents and their sources for every stream analysed; measured per tonne of given resource.

\begin{tabular}{llllll}
\hline Resource stream $(\mathrm{RS})$ & Value $(\mathrm{t} \mathrm{C} / \mathrm{t})$ & Source & Resource stream & Value & Source \\
\hline Coking/ BF Injection coal & 0.81 & (Worldsteel, & Natural gas & 0.015 & \\
$\begin{array}{l}\text { Home/external coke/breeze } \\
\text { Pet coke }\end{array}$ & 0.88 & 2015b) & BFG & 0.07 & (IPCC, 2006) \\
$\begin{array}{l}\text { Pig iron/hot metal/scrap } \\
\text { iron }\end{array}$ & 0.87 & & BOS & 0.01 & (Worldsteel, \\
$\begin{array}{l}\text { Crude/rolled steel/scrap } \\
\text { steel }\end{array}$ & 0.01 & & & 0.05 & 2015b) \\
$\begin{array}{l}\text { Crude dolomite } \\
\text { Limestone }\end{array}$ & 0.13 & (IPCC, 2006) & LPG/Waste tires & 0.02 t C/ GJ & \\
$\begin{array}{l}\text { BF Gas Dust/sludge } \\
\text { Tar/benzole }\end{array}$ & 0.12 & & Heavy/light oil & 0.02 t C/ GJ & (IEA, 2015b) \\
\hline
\end{tabular}

Table 9 compares the physical exergy calculations to values reported by de Beer et al. (1998) and Li et al. (2010). The main difference lies in the temperatures and physical properties assumed (specific heating values); the study by de Beer et al. (1998) uses maximum rather than average temperatures for most flows, and therefore yields higher values overall. Other differences may from differences in the $\mathrm{C}_{\mathrm{p}} \mathrm{s}$ used. The data provided by Li et al. (2010) is reported in energy, but is comparable to the $5.5 \mathrm{GJ} / \mathrm{t}_{\text {rolled steel }}$ quoted by de Beer et al. (1998). The physical exergy from the sinter plant is not disaggregated into sinter exhaust and cooling gases, but expressed as the physical exergy of the sinter output. The reheating furnace, boiler flue gases or EAF waste gas are not included.

Table 9- Physical exergy available. E stands for energy; B stands for exergy. rs stands for rolled steel.

\begin{tabular}{lcccccccc}
\hline \multirow{2}{*}{ Resource flow } & \multicolumn{2}{c}{ de Beer et al. $(1998)$} & \multicolumn{2}{c}{ IEA $(2007)$} & \multicolumn{2}{c}{ Li et al. $(2010)$} & \multicolumn{2}{c}{ This study } \\
& $\mathrm{E}$ & $\mathrm{T}\left({ }^{\circ} \mathrm{C}\right)$ & $\mathrm{B}\left(\mathrm{GJ} / \mathrm{t}_{\mathrm{rs}}\right)$ & $\mathrm{T}\left({ }^{\circ} \mathrm{C}\right)$ & $\mathrm{E}$ & $\mathrm{T}\left({ }^{\circ} \mathrm{C}\right)$ & $\mathrm{B}\left(\mathrm{GJ} / \mathrm{t}_{\mathrm{cs}}\right)$ & $\mathrm{T}\left({ }^{\circ} \mathrm{C}\right)$ \\
\hline Coke & 0.24 & 1100 & 0.14 & 1100 & 0.6 & 1000 & 0.20 & 800 \\
COG & 0.24 & 700 & 0.12 & 850 & 0.2 & 700 & 0.11 & 500 \\
Sinter cooler gas & 0.97 & 350 & 0.28 & $100-350$ & - & - & - & - \\
Sinter exhaust gas & 0.23 & 350 & 0.12 & $100-350$ & 0.7 & 300 & - & - \\
Sinter & - & - & - & - & 0.9 & 800 & 0.32 & 700 \\
WHR in hot stove & - & - & 0.33 & $250-400$ & - & - & - & - \\
BFG & 0.82 & 500 & - & - & 0.8 & 200 & 0.73 & 350 \\
BF slag & 0.39 & 1300 & 0.26 & 1500 & 0.6 & 1500 & 0.29 & 1200 \\
BOSG & 0.29 & 1200 & 0.12 & 1600 & 0.2 & 1600 & 0.04 & 1200 \\
BOF slag & 0.02 & 1500 & 0.01 & 1600 & 0.2 & 1550 & 0.08 & 1200 \\
Cast steel slab & 1.39 & 1600 & 1.06 & 1600 & - & - & 0.55 & 1300 \\
Hot rolled steel & 1.04 & 900 & 0.62 & 900 & 0.6 & 900 & 0.28 & 900 \\
\hline Total & 5.5 & & 3.06 & & 4.90 & & 2.55 & \\
\hline
\end{tabular}

To validate the global resource flows obtained in this study, numbers were cross-checked across other reliable data sources. These are summarised in Table 10. This study calculates the average exergy input to the global steel industry as $24.7 \mathrm{GJ} / \mathrm{t}_{\mathrm{cs}}$. This is larger than the equivalent energy intensity $20.7 \mathrm{GJ} / \mathrm{t}_{\mathrm{cs}}$ reported by the IEA (2014) for 2011 , as the material inputs are included in the exergy analysis.

\footnotetext{
${ }^{1}$ It is unclear whether the $\mathrm{C}$ contents reported by worldsteel are global averages or best practice. To to obtain more accurate $\mathrm{CO}_{2}$ emissions results, we would need to have specific measurement of carbon content and net caloric value from each site.
} 
Table 10- Data validation through comparisons of specific results to other relevant studies

\begin{tabular}{lccccc}
\hline Resource flow & Unit & This study & Literature & \% Diff & Reference \\
\hline Total coal input & EJ (energy) & 23.2 & 24.4 & 5 & (World Coal Institute, 2007) \\
Fraction of EAF to BOF & $\%$ & 27 & 29 & 7 & (IEA, 2017b) \\
Coke input into BF & EJ (energy) & 12.4 & 12.3 & 1 & \\
Tar produced in CO & EJ (energy) & 0.44 & 0.48 & 9 & \\
BFG production & EJ & 4.8 & 5.2 & 8 & (IEA, 2010) \\
COG production & EJ & 2.8 & 2.8 & 1 & \\
\hline
\end{tabular}

Figure 6 depicts the fraction of waste gases fed into the different parts of the production route.

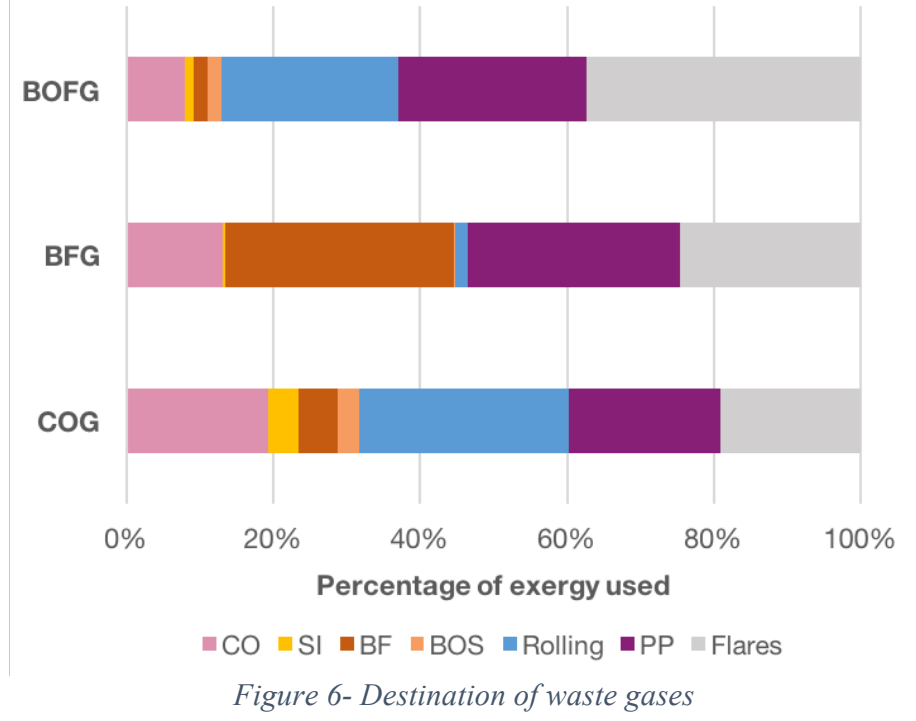

Table 11 summarises the exergy losses arising from mass losses, $\mathrm{CO}_{2}$ emissions and irreversibilities. The latter can be divided into four categories, depending on the mechanism behind it: combustion and other reactions, heat transfer or expansion and compression. The irreversibilities breakdown was calculated following work by de Beer et al. (1998).

Table 11- Summary of exergy losses for seven processes, divided into the exergy in the mass loss, that in $\mathrm{CO}_{2}$ emissions and Irreversibilities; measured in gigajoules per tonne of crude steel.

\begin{tabular}{lcccccccc}
\hline Exergy loss & CO & SI & BF & BOS & EAF & HSM & PP & Total \\
\hline Mass loss & 0.7 & 0.09 & 1.4 & 0.5 & 0.01 & 0.1 & 0.0 & 3.0 \\
$\mathrm{CO}_{2}$ emissions & 0.2 & 0.2 & 0.3 & 0.0 & 0.0 & 0.03 & 0.2 & 0.9 \\
Total irreversibilities & 1.2 & 1.8 & 2.8 & 0.8 & 0.9 & 0.7 & 1.3 & 11.0 \\
\hline
\end{tabular}

\section{References}

Akiyama, T., Yagi, J.-, 1988. Exergy Analysis of Conventional Ironmaking, Direct Reduction-Electric Furnace and Smelting Reduction Systems. Iron steel Ind. Japan 2270-2277.

Allwood, J.M., 2014. Squaring the Circular Economy: The Role of Recycling within a Hierarchy of Material Management Strategies.

Allwood, J.M., Cullen, J.M., Milford, R.L., 2010a. Options for achieving a 50\% cut in industrial carbon emissions by 2050. Environ. Sci. Technol. 44, 1888-1894.

Allwood, J.M., Cullen, J.M., Milford, R.L., 2010b. Options for achieving a 50\% cut in industrial carbon emissions by 2050. Environ. Sci. Technol. 44, 1888-1894. https://doi.org/10.1021/es902909k

Arens, M., Worrell, E., 2014. Diffusion of energy efficient technologies in the German steel industry and their impact on energy consumption. Energy 73, 968-977. https://doi.org/https://doi.org/10.1016/j.energy.2014.06.112 
Ayres, R.U., Ayres, L.W., 1999. Accounting for resources, 2: The life-cycle of materials. Edward Elgar Publishing Limited.

Ayres, R.U., Peiró, L.T., Méndez, G.V., 2011. Exergy efficiency in industry: where do we stand? Environ. Sci. Technol.

Banerjee, R., Cong, Y., Gielen, D., Jannuzzi, G., Maréchal, F., McKane, A.T., Rosen, M.A., van Es, D., Worrell, E., 2012. Chapter 8 - Energy End Use: Industry, in: Global Energy Assessment - Toward a Sustainable Future. Cambridge University Press, Cambridge, UK and New York, NY, USA and the International Institute for Applied Systems Analysis, Laxenburg, Austria, pp. 513-574.

Bisio, G., 1993. Exergy method for efficient energy resource use in the steel industry. Energy 18, 971-985. https://doi.org/10.1016/0360-5442(93)90007-Z

Branham, M., Gutowski, T.G., Jones, A., Sekulic, D.P., 2008. A Thermodynamic Framework for Analyzing and Improving Manufacturing Processes.

Brodyansky, V., Sorin, M., Le Goff, P., Pilavachi, P.., 1994. The efficiency of industrial processes: exergy analysis and optimization. Elsevier.

Canadian Steel Producers Association, 2007. Benchmarking Energy Intensity in the Canadian Steel Industry.

Carpenter, A., 2012. CO2 abatement in the iron and steel industry. IEA Clean Coal Cent.

Cooper, D.R., Skelton, A.C.H., Moynihan, M.C., Allwood, J.M., 2014. Component level strategies for exploiting the lifespan of steel in products. Resour. Conserv. Recycl. 84, 24-34.

Costa, M.M., Schaeffer, R., Worrell, E., 2001. Exergy accounting of energy and materials flows in steel production systems. Energy 26, 363-384. https://doi.org/10.1016/S0360-5442(01)00004-4

Cullen, J., Allwood, J., 2012. Sustainable Materials: With both eyes open.

Daehn, K.E., Cabrera Serrenho, A., Allwood, J.M., 2017. How Will Copper Contamination Constrain Future Global Steel Recycling? Environ. Sci. Technol. 51, 6599-6606. https://doi.org/10.1021/acs.est.7b00997

de Beer, J., Worrell, E., Blok, K., 1998. Future technologies for energy-efficient iron and steel making. Annu. Rev. Energy Environ. 123-205.

Densley Tingley, D., Cooper, S., Cullen, J., 2017. Understanding and overcoming the barriers to structural steel reuse, a UK perspective. J. Clean. Prod. 148, 642-652. https://doi.org/https://doi.org/10.1016/j.jclepro.2017.02.006

ESTEP/EUROFER, 2014. Steel production - energy efficiency working group.

European Commission, 2016. Definition of ODEX indicators in ODYSSEE database.

European Commission, 2015. Assessment of the progress made by Member States towards the national energy efficiency targets for 2020 and towards the implementation of the Energy Efficiency Directive 2012/27/EU as required by Article 24 (3) of Energy Efficiency Directive 2012/27/EU.

European Commission, 2009. Reference Document on Best Available Techniques for Energy Efficiency, BREF.

Eurostat, 2016. Energy balance flow for the European Union (2015) [WWW Document].

Gonzalez Hernandez, A., Paoli, L., Cullen, J.M., 2017. Global average resource flow data for the steel industry. https://doi.org/10.17863/CAM.10564

Graedel, T.E., Allwood, J.M., Birat, J.-P., Buchert, M., Hagelüken, C., Reck, B.K., Sibley, S.F., Sonnemann, G., 2011. What do we know about metal recycling rates? J. Ind. Ecol. 15.

Gutowski, T.G., Branham, M.S., Dahmus, J.B., Jones, A.J., Thiriez, A., Sekulic, D.P., 2009. Thermodynamic Analysis of Resources Used in Manufacturing Processes. Environ. Sci. Technol. 43, 1584-1590. https://doi.org/10.1021/es8016655

Humphris-Bach, A., Essig, C., Morton, G., Harding, L., 2015. EU Resource efficiency scoreboard.

IEA, 2017a. Energy Technology Perspectives 2017: Catalysing Energy Technology Transformations. https://doi.org/10.1787/energy tech-2017-en

IEA, 2017b. Energy Technology Perspectives: Catalysing energy technology transformations. Paris, France. https://doi.org/http://dx.doi.org/10.1787/energy_tech-2017-en

IEA, 2016. Energy Technology Perspectives: Towards sustainable urban energy systems.

IEA, 2015a. World Energy Outlook. Paris, France.

IEA, 2015b. CO2 emissions from fuel combustion: highlights. https://doi.org/http://dx.doi.org/10.1787/co2_fuel2015-en

IEA, 2014. Energy Technology Perspectives.

IEA, 2010. World Energy Balances online data service.

IEA, 2007. Tracking Industrial Energy Efficiency and CO2 Emissions.

IISI, 1998. Energy Use in the Steel Industry. Brussels.

IPCC, 2006. Metal Industry Emissions, in: IPCC Guidelines for National GReenhouse Gas Inventories.

Keenan, J.H., 1932. A steam chart for second-law analysis, a study of thermodynamic availability in the steam power plant. Mech. Eng. 54, 195-204.

Kuramochi, T., 2016. Assessment of midterm CO2 emissions reduction potential in the iron and steel industry: a case of Japan. J. Clean. Prod. 132, 81-97. https://doi.org/https://doi.org/10.1016/j.jclepro.2015.02.055 
Lally, B., Biegler, L.T., Henein, H., 1990. Finite Difference Heat-Transfer Modeling for Continuous Casting. Metall. Trans. B 21, 761-770.

Li, H., Bao, W., Cang, D., 2010. Energy recovery and abatement potential of CO2 emissions for an integrated iron and steel making enterprise. Sci. China. Ser. E Technol. Sci. 53, 129-133.

Loison, R., Foch, P., Boyer, A., 1989. Coke: quality and production., 2nd editio. ed. Butterworths.

Masini, A., Ayres, R.U., 1996. An application of exergy accounting to five basic metal industries. Sustain. Met. Manag. 141-194. https://doi.org/10.1007/1-4020-4539-5_6

Michaelis, P., Jackson, T., Clift, R., 1998. Exergy analysis of the life cycle of steel, Energy. https://doi.org/10.1016/S0360-5442(97)00081-9

Milford, R.L., Allwood, J.M., Cullen, J.M., 2011. Assessing the potential of yield improvements, through process scrap reduction, for energy and $\mathrm{CO} 2$ abatement in the steel and aluminium sectors. Resour. Conserv. Recycl. 55, 1185-1195.

Milford, R.L., Pauliuk, S., Allwood, J.M., Müller, D.B., 2013. The Roles of Energy and Material Efficiency in Meeting Steel Industry CO2 Targets. Environ. Sci. Technol. 47, 3455-3462. https://doi.org/10.1021/es3031424

Monaghan, B.J., Brooks, R.F., 2002. Thermophysical properties of slags for process control. Ironnmaking Steelmak. 29, 115-120. https://doi.org/10.1179/030192302225003468

Morfeldt, J., Nijs, W., Silveira, S., 2015. The impact of climate targets on future steel production - An analysis based on a global energy system model. J. Clean. Prod. 103, 469-482. https://doi.org/10.1016/j.jclepro.2014.04.045

Nakicenovic, N., Gilli, P.V., Kurz, R., 1996. Regional and global exergy and energy efficiencies. Energy 21, 223237.

OECD/IEA, 2007. Tracking Industrial Energy Efficiency and CO2 Emissions. Paris, France.

Ostrovski, O., Zhang, G., 2005. Energy and exergy analyses of direct ironsmelting processes. Energy 30, 27722783. https://doi.org/10.1016/j.energy.2005.01.007

Pauliuk, S., Milford, R.L., Müller, D.B., Allwood, J.M., 2013. The Steel Scrap Age. Environ. Sci. Technol. 47, 3448-3454. https://doi.org/10.1021/es303149z

Petela, R., Hutny, W., Price, J.T., 2002. Energy and exergy consumption and CO2 emissions in an ironmaking process. Adv. Environ. Res. 6, 157-170. https://doi.org/10.1016/S1093-0191(01)00118-6

Phylipsen, D., Blok, K., Worrell, E., Beer, J. de, 2002. Benchmarking the energy efficiency of Dutch industry: an assessment of the expected effect on energy consumption and CO2 emissions. Energy Policy 30, 663-679. https://doi.org/https://doi.org/10.1016/S0301-4215(02)00023-X

Phylipsen, G., Blok, K., Worrell, E., 1997. International comparisons of energy efficiency- Methodologies or the manufacturing industries. Energy Policy 25, 715-725.

Rant, Z., 1956. Exergy, a New Word for Technical Available Work. Forsch. Ing. Wis. 22, 36-37.

Saygin, D., 2012. Assessing industrial energy use and CO2 emissions: opportunities for energy efficiency, biomass and ccs. Utrecht University.

Siitonen, S., Tuomaala, M., Ahtila, P., 2010. Variables affecting energy efficiency and CO2 emissions in the steel industry. Energy Policy 38, 2477-2485. https://doi.org/10.1016/j.enpol.2009.12.042

Sorin, M., Paris, J., 1998. EXERGY EFFICIENCY AND CONVERSION OF CHEMICAL REACTIONS 39.

Spittel, M., Spittel, T., 2009. 4.4 Specific heat capacity of steel, in: Warlimont, H. (Ed.), Metal Forming Data of Ferrous Alloys - Deformation Behaviour. Springer Berlin Heidelberg, Berlin, Heidelberg, pp. 98-103. https://doi.org/10.1007/978-3-540-44760-3_8

Szargut, J., 1986. Standard chemical exergy of some elements and compounds on the planet Earth. Energy 11, 733755.

Szargut, J., Egzergia, 2007. Appendix 1. Standard chemical exergy.

Szargut, J., Morris, D., Steward, F., 1988. Exergy analysis of thermal, chemical and metallurgical processes. Hemisphere Publishing Corporation.

Szargut, J., Morris, D.R., Steward, F.R., 1988. Exergy Analysis of Thermal, Chemical, \& Metallurgical Processes. Hemisphere Publishing Corporation, New York.

Tian, F.-Y., Huang, L.-F., Fan, L.-W., Weng, Y.-K., Ying, X.-Y., Yu, Z.-T., Cen, K.-F., 2015. A comprehensive characterization on the structural and thermophysical properties of sintered ore particles toward waste heat recovery applications. Appl. Therm. Eng. 90, 1007-1014. https://doi.org/10.1016/j.applthermaleng.2015.07.071

Trung, Z.H., Kukurugya, F., Takacova, Z., Orac, D., Laubertova, M., Miskufova, A., Havlik, T., 2011. Acidic leaching both of zinc and iron from basic oxygen furnace sludge. J. Hazard. Mater. 192, 1100-1107. https://doi.org/https://doi.org/10.1016/j.jhazmat.2011.06.016

UNIDO, 2010. Global Industrial Energy Efficiency Benchmarking: an energy policy tool working paper. United Nations Ind. Dev. Organ.

van Ruijven, B.J., van Vuuren, D.P., Boskaljon, W., Neelis, M.L., Saygin, D., Patel, M.K., 2016. Long-term 
model-based projections of energy use and $\mathrm{CO} 2$ emissions from the global steel and cement industries.

Resour. Conserv. Recycl. 112, 15-36. https://doi.org/https://doi.org/10.1016/j.resconrec.2016.04.016

Waugh, R.L., 2013. Options for achieving a 50\% reduction in steel industry Co2 emissions by 2050. University of Cambridge.

World Coal Institute, 2007. Coal \& Steel report.

Worldsteel, 2016. Fact sheet: steel industry by-products.

Worldsteel, 2015a. Worldsteel 2010-2015 datasets. Brussels, Belgium.

Worldsteel, 2015b. CO2 Emissions Data Collection: User Guide, Version 7.

Worldsteel, 2014. Energy use in the steel industry. Brussels.

Worrell, E., Price, L., Neelis, M., Galitsky, C., Nan, Z., 2008. World Best Practice Energy Intensity Values for Selected Industrial Sectors 51.

Wu, J., Wang, R., Pu, G., Qi, H., 2016. Integrated assessment of exergy, energy and carbon dioxide emissions in an iron and steel industrial network. Appl. Energy 183, 430-444. https://doi.org/10.1016/j.apenergy.2016.08.192

Zhang, H., Wang, H., Zhu, X., Qiu, Y., Li, K., Chen, R., Liao, Q., 2013. A review of waste heat recovery technologies towards molten slag in steel industry. Appl. Energy 112, 956-966. https://doi.org/10.1016/j.apenergy.2013.02.019

Zhang, Q., Xu, J., Wang, Y., Hasanbeigi, A., Zhang, W., Lu, H., Arens, M., 2018. Comprehensive assessment of energy conservation and $\mathrm{CO} 2$ emissions mitigation in China's iron and steel industry based on dynamic material flows. Appl. Energy 209, 251-265. https://doi.org/https://doi.org/10.1016/j.apenergy.2017.10.084 